\title{
Interactive comment on "Identifying urban areas prone to flash floods using GIS - preliminary results" by Marzena Wicht and Katarzyna Osinska-Skotak
}

\author{
N. Phelan \\ nickgphelan@gmail.com \\ Received and published: 16 December 2016
}

A Review of "Identifying urban areas prone to flash floods using GIS - preliminary results" - by Marzena Wicht and Katarzyna Osinka - Skotak

This paper proposes a modeling methodology for the identification of urban areas that are vulnerable to flash floods, and classifying them based on their level of risk. The paper has a very practical application in the world today, and may help decision makers better develop and protect their citizens and infrastructure. However, the paper requires much rewriting, clarification, and more detailed information regarding what it is that makes it innovative for it to be accepted. Please see my suggestions for how to improve to paper, as well as, suggestions on how to improve the wording.

Printer-friendly version

Discussion paper 
1) While reading this paper, I found many adjectives that are unnecessary, and other adjectives that may be very descriptive but with no descriptions. For example:

a. P.1-L.2 "consistent methodology" scientific methods are consistent by nature.

b. P.1-L.2 "particularly vulnerable" I understand that the particularities may be explained later, but I believe a more descriptive wording would be beneficial.

Interactive

C. P.1-L.7 "torrential rains" The word torrential does not have a specific measurement itself, so if it is used you may wish to elaborate on the intensity of this rainfall.

d. P.1-L19 "violent weather" Like torrential, it is important for the reader to understand the meaning of violent. Although I understand you are citing from Gaume et al. 2009, however they do not use the word violent.

e. P1.1-L24 "valid threat" validation of a threat may have to be discussed if the word valid is used. I understand this word adds colour and emphasis to the statement, but simply saying it presents a threat to the inhabitants is good enough.

Spelling mistakes, and improper or awkward use of words are found throughout this paper and highly impact the way this very interesting paper is delivered.

2) The Introductory section introduces elements in an awkward fashion. I believe the whole section (and whole paper) should be restructured to clearly introduce the flood risk mitigation modeling, its limitations, and opportunities. I believe introducing subchapter sections and clearly explain the relevance of each should be easily done, as this paper indicates a high level of thought and research has already been put into it. Here is my proposal using some of the themes, and information you spoke of in the introduction. This is not necessarily the best way to present this paper, but I believe something along these lines will greatly improve the foundation for which you will be producing a methodology.

1. Introduction 1.1 Changing Weather 1.2 The nature of Urban centers 1.3 Availability of Data and Data Processing 1.4 Elements and Indicators That Influence Vulnerability

Printer-friendly version

Discussion paper 
3) P.2-L13 which open-access (GIS) platform are you speaking of? Is it called GIS? A graphical information system (GIS), is a system, and there are many platforms that utilize standardized data structures, QGIS for example. Perhaps it is that municipalities have open-access GIS data available. This needs to be clarified along with P.2-L.15 "GIS tools".

4) I think you should introduce all elements of chapter 2 "Data and methods" into the introduction. Most of the information here is introductory into the advancement and availability of data and technology. Some information in these parts can be placed later in chapter 3 "design of experiment and methodology". For example: P.9-L3 "during preliminary trials ..." This information would go very well in the design/ development of the experiment.

5) Chapter 3 is well broken down into subsections, and contains some very good information. However, it often lacks the justification and emphasis to achieve the goal of producing a generalized methodology. I believe you can easily fix this by clearly explaining each possible input and their short comings. It may be helpful for the subchapter headings to be the same as those in the model design figure headings, and explain each step by step this way.

6) You mention anthropogenic soil, and its importance to hydrology, I believe further emphasis can be placed on this, to explain how it is incorporated into the methodology as well as its sensitivity analysis on the results.

7) The first sentence of the conclusion should be like the first statement of the introduction. Something like "A methodology for identifying at risk areas has been accomplished.".

The Sentence (P.16-L.32) "Flash floods in urban areas..." is poorly written and introduces information not spoken about during the paper (social aspects regarding hydro- 
logical studies). If this needs to be included, it should be introduced properly within the introduction section, and refer to certain Socio-Hydrology publications (Like Wheater, Montanari, or others) I believe it could be elaborated on when discussing the availability of data and data processing.

8) Identifying what makes the approach presented innovative. The methodology design seems appropriate as argued. I believe it can be elaborated upon, further utilization of the works of model creation and analysis from Gupta's work.

9) The addition of storm water infrastructure into the model will add a level of innovation and is worth mentioning in the design methodology. This may be the most innovative and worth elaborating on.

Interactive comment on Hydrol. Earth Syst. Sci. Discuss., doi:10.5194/hess-2016-518, 2016. 